\section{The influence of carotid artery occlusion on the occurrence of nonfocal cerebral symptoms}

Eline J Volkers, ${ }^{1,2}$ Eline A Oudeman, ${ }^{1}$ Jacoba P Greving, ${ }^{2}$ Ale Algra, ${ }^{1,2}$ $L$ Jaap Kappelle; ${ }^{1}$ on behalf of the HBC and SMART Study Groups

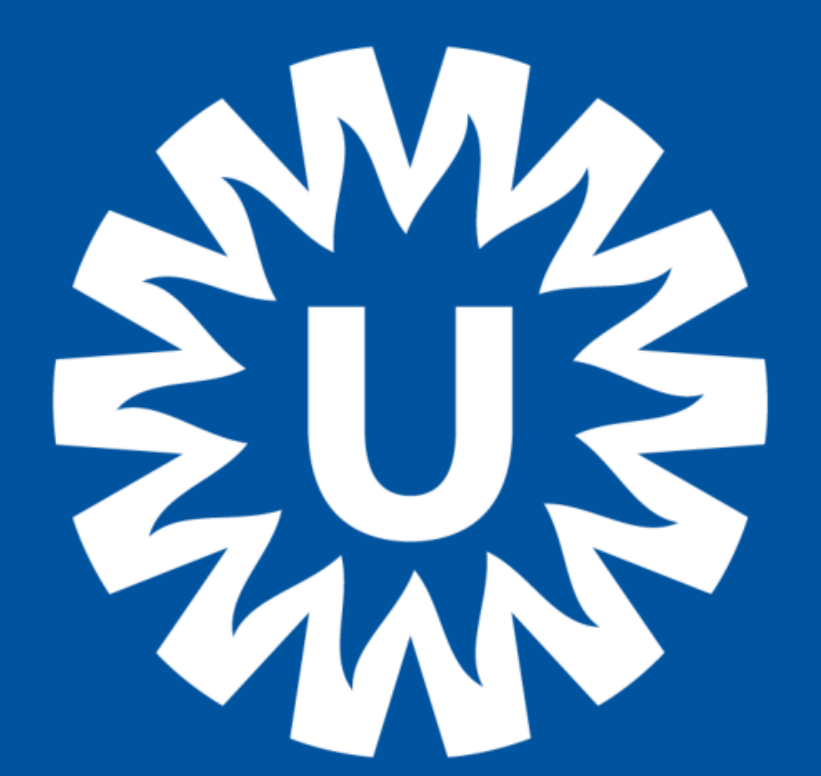

UMC Utrecht

Center for Circulatory Health

Brain Center Rudolf Magnus Julius Center

1 Department of Neurology and Neurosurgery, Brain Centre Rudolf Magnus, University Medical Centre Utrecht, Utrecht, the Netherlands; 2 Julius Centre for Health Sciences and Primary Care, University Medical Centre Utrecht, Utrecht, the Netherlands.

\section{Introduction}

- Nonfocal cerebral symptoms are atypical, nonlocalizing symptoms, such as unsteadiness or dizziness

- The occurrence of nonfocal cerebral symptoms is associated with a higher risk of cardiovascular events and dementia ${ }^{1}$

- Nonfocal cerebral symptoms have not been studied in patients with carotid artery occlusion, but have been reported more frequently in patients with carotid artery stenosis ${ }^{2}$

\section{Aim}

To study the relationship between carotid artery occlusion and the occurrence of nonfocal cerebral symptoms

\section{Hypothesis}

Nonfocal cerebral symptoms occur more often in patients with carotid artery occlusion due to cerebral hypoperfusion

\section{Results}

- Mean age was $65.3( \pm 7.9)$ in patients with and 65.8 $( \pm 9.8)$ in patients without carotid artery occlusion

- Most often reported symptom was unsteadiness in both groups ( $45 \%$ vs. $26 \%$ )

Table 1. Occurrence of different types of nonfocal cerebral symptoms in past six months

\begin{tabular}{|l|cc|} 
Nonfocal symptoms, $\mathrm{n}(\%)$ & $\begin{array}{c}\text { Carotid occlusion } \\
(\mathrm{n}=67)\end{array}$ & $\begin{array}{c}\text { No carotid } \\
\text { occlusion }(\mathrm{n}=62)\end{array}$ \\
\hline Blurred vision & $6(9 \%)$ & $2(3 \%)$ \\
Bilateral weakness & $4(6 \%)$ & $1(2 \%)$ \\
Unsteadiness & $30(45 \%)$ & $16(26 \%)$ \\
Isolated vertigo & $6(9 \%)$ & $0(0 \%)$ \\
Nonrotatory dizziness & $18(27 \%)$ & $13(21 \%)$ \\
Paraesthesias & $0(0 \%)$ & $4(7 \%)$ \\
Unconsciousness & $4(6 \%)$ & $0(0 \%)$ \\
Confusion & $2(3 \%)$ & $0(0 \%)$ \\
Amnesia & $1(2 \%)$ & $0(0 \%)$ \\
\hline
\end{tabular}

1 Bos JAMA 2007;298:2877-2885; 2 Compter Cerebrovasc Dis 2013;35:378-384

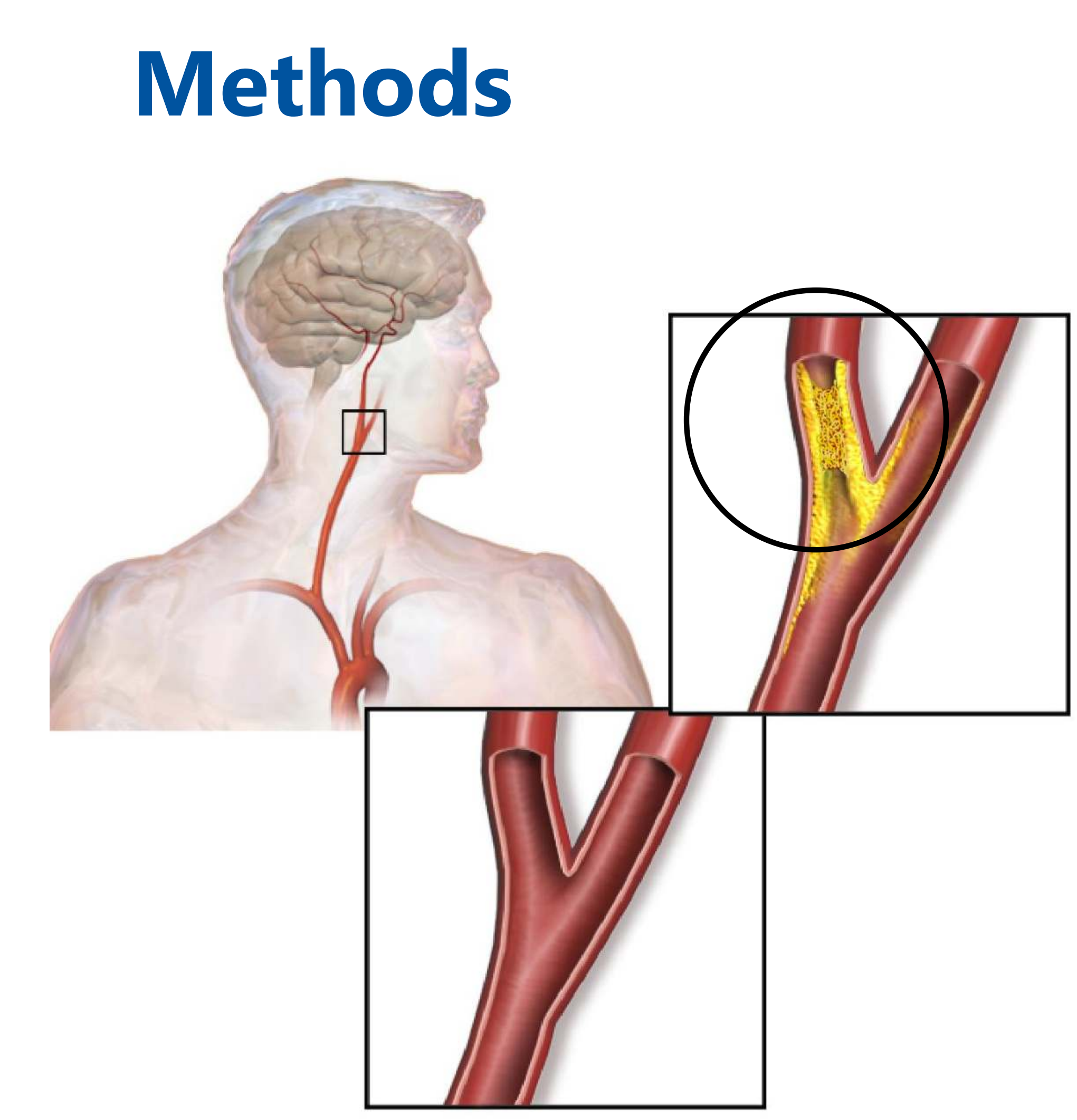

Patients with carotid artery occlusion

- Multicentre Heart-Brain Study

- November 2014-February 2017

- Ever-symptomatic carotid occlusion

Patients without carotid artery occlusion

- Single centre SMART Study

- November 2015-September 2017

- $<50 \%$ carotid arteries stenosis on recent imaging (performed $<1$ year ago)

- All patients had a history of TIA or ischaemic stroke of the anterior circulation that had occurred $>6$ months ago

- All patients were interviewed with a standardised questionnaire on the occurrence of nonfocal cerebral symptoms in the preceding 6 months

- We calculated risk ratios (RRs) of the occurrence of nonfocal cerebral symptoms

Figure. Number of different types of nonfocal cerebral symptoms in past six months

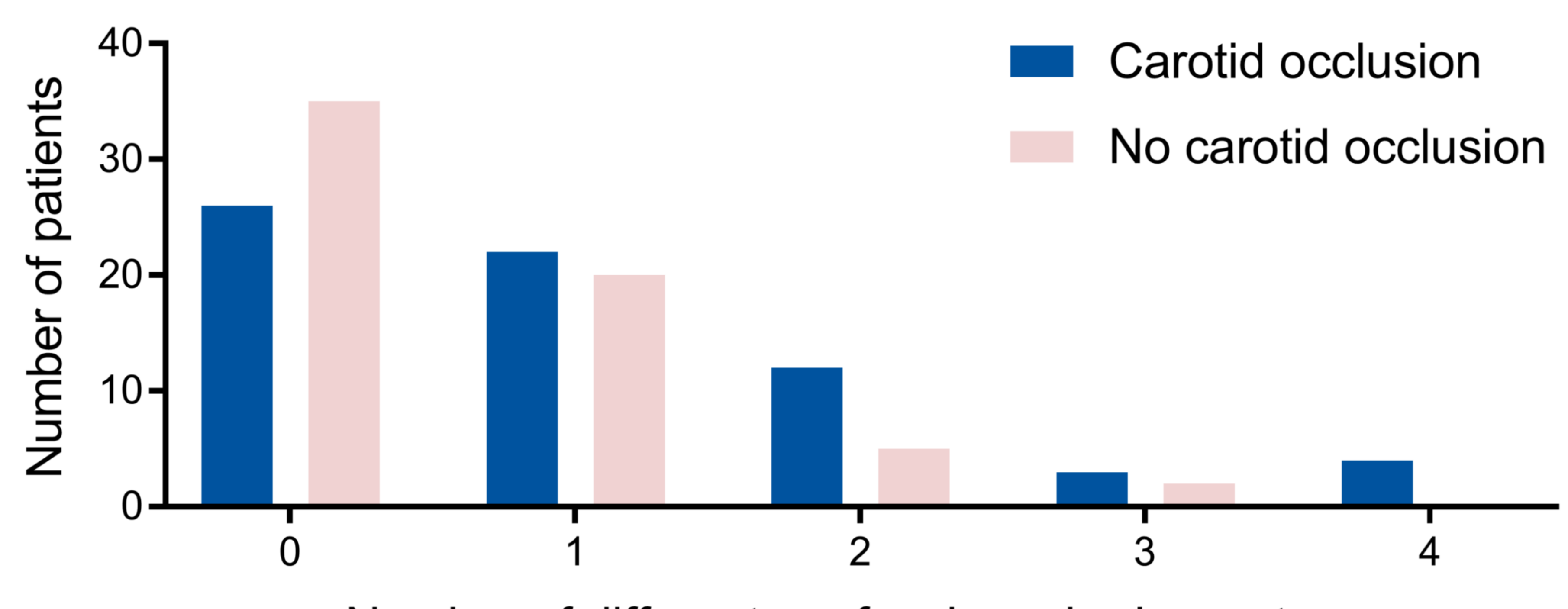

Number of different nonfocal cerebral symptoms

Table 2. Occurrence of nonfocal cerebral symptoms in past six months in patients with and without carotid artery occlusion

\begin{tabular}{|l|c|c|c|c|} 
Occurrence of, $\mathrm{n}(\%)$ & $\begin{array}{c}\text { Carotid occlusion } \\
(\mathrm{n}=67)\end{array}$ & $\begin{array}{c}\text { No carotid } \\
\text { occlusion }(\mathrm{n}=62)\end{array}$ & $\begin{array}{c}\text { RR crude } \\
(95 \% \mathrm{Cl})\end{array}$ & $\begin{array}{c}\text { RR adjusted } \\
(95 \% \mathrm{Cl})^{*}\end{array}$ \\
\hline$\geq 1$ different symptoms & $41(61 \%)$ & $27(44 \%)$ & $\begin{array}{c}1.41 \\
(1.00-1.98)\end{array}$ & $\begin{array}{c}1.46 \\
(1.00-2.14)\end{array}$ \\
\hline$\geq 2$ different symptoms & $19(28 \%)$ & $7(11 \%)$ & $\begin{array}{c}2.51 \\
(1.14-5.56)\end{array}$ & $\begin{array}{c}3.32 \\
(1.56-7.10)\end{array}$ \\
\hline
\end{tabular}

*Adjusted for: age, use of antihypertensive medication, time between most recent TIA or ischaemic stroke and interview

\section{Conclusion}

Patients with carotid artery occlusion more often experience nonfocal cerebral symptoms than patients without carotid artery occlusion 